\title{
INDEKS MASSA TUBUH DAN KEJADIAN JERAWAT PADA SISWA-SISWI SMA MUHAMMADIYAH 1 PONTIANAK
}

\author{
Safira Sukma Dewinda ${ }^{1}$, Ambar Rialita $^{2}$, Mahyarudin $^{3 凶}$ \\ ${ }^{1}$ Jurusan Kedokteran Universitas Tanjungpura \\ ${ }^{2}$ Departemen Kulit dan Kelamin Fakultas Kedokteran Universitas Tanjungpura \\ ${ }^{3}$ Departemen Mikrobiologi Fakultas Kedokteran Universitas Tanjungpura
}

\section{ARTICLE INFO \\ Article history}

Submitted : 2020-03-16

Revised : 2020-10-27

Accepted : 2020-12-28

\section{Keywords:}

Acne vulgaris

BMI

Students

\section{Kata Kunci:}

Acne vulgaris

$I M T$

Siswa

\begin{abstract}
Acne vulgaris affects about $85 \%$ of adolescents and can last into adulthood. One of the factors that influence the pathogenesis of acne vulgaris is androgens. Androgens have an essential role in stimulating sebum production, which has a significant role in the pathogenesis of acne vulgaris. Obesity is often accompanied by peripheral hyperandrogenism. Obesity can affect the sebaceous glands and sebum production, which is the major factor in the relationship between acne vulgaris and obesity. The purpose of this study was to determine the relationship between Body Mass Index and the incidence of acne vulgaris. This study used an observational analytic research design with a cross-sectional approach. The study was conducted at Muhammadiyah 1 Pontianak Senior High School. Samples were taken using simple random sampling. The independent variable in this study was the body mass index while the dependent variable in this study was acne vulgaris. Sampling was conducted by simple random sampling. We used a logistic regression test for data analysis. The results showed that $61 \%$ of students experienced acne vulgaris, and $20.7 \%$ of students were obese. The statistical test result showed there was a significant positive correlation relationship between BMI and the incidence of acne vulgaris with a value of $\mathrm{p}<0.05$ and OR 2.807. This study concluded that there was a significant positive correlation between BMI and the incidence of acne vulgaris. The incidence of acne vulgaris increased by 2,807 times as the increase of BMI among students in Muhammadiyah 1 Pontianak Senior High School.

Acne vulgaris mempengaruhi sekitar $85 \%$ remaja dan dapat bertahan sampai dewasa. Faktor yang mempengaruhi patogenesis acne vulgaris satu di antaranya, yaitu hormon androgen. Androgen memiliki peranan yang esensial dalam menstimulasi produksi sebum, yang memiliki peran signifikan dalam patogenesis acne vulgaris. Obesitas sering disertai dengan hiperandrogenisme perifer. Obesitas dapat mempengaruhi kelenjar sebasea dan produksi sebum yang menjadi faktor utama hubungan acne vulgaris dan obesitas. Tujuan penelitian ini untuk mengetahui hubungan Indeks Massa Tubuh dan kejadian acne vulgaris. Penelitian ini menggunakan desain penelitian analitik observasional dengan pendekatan cross-sectional. Penelitian dilakukan di SMA Muhammadiyah 1 Pontianak. Sampel diambil dengan metode acak sederhana. Variabel bebas dalam penelitian ini adalah indeks massa tubuh sedangkan variabel terikat dalam penelitian ini adalah acne vulgaris. Pengambilan sampel dilakukan dengan cara simple random sampling. Analisis data pada penelitian ini menggunakan uji regresi logistik. Hasil penelitian menunjukkan sebanyak $61 \%$ siswa-siswi mengalami acne vulgaris dan sebanyak 20.7\% siswa-siswi mengalami obesitas. Hasil uji statistik menunjukkan terdapat hubungan korelasi positif yang bermakna antara IMT dan kejadian acne vulgaris dengan nilai $\mathrm{p}<0.05$ dan OR 2.807 . Kesimpulan dari penelitian ini adalah terdapat hubungan korelasi positif yang bermakna antara IMT dan kejadian acne vulgaris. Kejadian acne vulgaris meningkat 2.807 kali seiring dengan peningkatan IMT pada siswa-siswi SMA Muhammadiyah 1 Pontianak.
\end{abstract}

Corresponding Author:

\section{Mahyarudin}

Departemen Mikrobiologi Fakultas Kedokteran Universitas Tanjungpura

Telp. 082150405040

Email: mahyarudin@medical.untan.ac.id

\section{PENDAHULUAN}

Acne vulgaris adalah inflamasi kelenjar sebaceous yang menyebabkan penyumbatan 
ekskresi sebum yang terakumulasi pada folikel. Hal tersebut menimbulkan terjadinya komedo. Setelah melewati tahap komedo, folikel pecah kemudian menyebabkan radang kulit dalam bentuk papula dan pustula (WHO, 2014).

Acne vulgaris mempengaruhi sekitar $85 \%$ remaja dan dapat bertahan sampai dewasa. Tidak ada mortalitas yang terkait dengan acne vulgaris, namun sering kali ada morbiditas fisik dan psikologis yang signifikan, seperti jaringan parut permanen, citra diri yang buruk, depresi, dan kecemasan. Biaya langsung penyakit ini diperkirakan melebihi \$3 miliar per tahun (Zaenglein AL, et al, 2016).

Acne vulgaris di Indonesia merupakan masalah kulit yang paling mengganggu remaja dan ditemukan pada sekitar $80 \%$ remaja. Acne vulgaris berkaitan dengan masalah kebersihan kulit, pola makan, hormonal, psikologis, dan infeksi bakteri. Acne vulgaris paling sering terjadi pada masa remaja dan dimulai pada awal pubertas. Insiden acne vulgaris pada remaja bervariasi antara 30-60\% dengan insiden terbanyak pada usia $14-17$ tahun pada perempuan dan 16 - 19 tahun pada laki-laki (IDAI, 2013).

Banyak faktor yang mempengaruhi patogenesis acne vulgaris salah satunya, yaitu androgen. Banyak penelitian dilakukan untuk mengetahui efek androgen pada acne vulgaris. Obesitas sering disertai hiperandrogenisme perifer, karena alasan ini obesitas mungkin terkait dengan perkembangan acne vulgaris berat (Alan S, 2014).

Kelebihan berat badan dan obesitas didefinisikan sebagai akumulasi lemak abnormal atau berlebihan yang menghadirkan risiko terhadap kesehatan. Kegemukan dan obesitas merupakan faktor risiko utama untuk sejumlah penyakit kronis. Acne vulgaris dianggap sebagai masalah bukan hanya di negara berpenghasilan tinggi akan tetapi, kelebihan berat badan dan obesitas sekarang meningkat secara dramatis di negara berpenghasilan rendah dan menengah, terutama di daerah perkotaan (WHO, 2018b). WHO menyatakan pada tahun 2016 39\% wanita dan $39 \%$ pria usia 18 tahun atau lebih mengalami kelebihan berat badan. Angka ini meningkat dari tahun 1975 sampai 2016. Data juga menunjukkan $18 \%$ dari anak-anak dan remaja usia 5 - 19 tahun mengalami kelebihan berat badan atau obesitas (WHO, 2018). Prevalensi obesitas di Indonesia sendiri mencapai $11,7 \%$ pada tahun 2010 dan meningkat menjadi 15,4\% pada tahun 2013 (Depkes RI, 2013; Lailani TM, 2013).

Penelitian hubungan IMT dengan acne vulgaris yang dilakukan di Surakarta, Indonesia, menyimpulkan bahwa terdapat hubungan yang signifikan antara IMT dan kejadian acne vulgaris (Pranitasari ARD, 2011). Prevalensi acne vulgaris yang tinggi dan kecenderungan peningkatan kelebihan berat badan maupun obesitas di Indonesia, perlu penelitian-penelitian tentang hubungan Indeks Massa Tubuh (IMT) dengan acne vulgaris. Penelitian ini tampaknya belum banyak dilakukan di Pontianak. Berdasarkan pemaparan di atas, belum adanya penelitian mengenai hubungan IMT dengan acne vulgaris sehingga penulis tertarik untuk meneliti hubungan antara Indeks Massa Tubuh (IMT) dengan terjadinya acne vulgaris di SMA Muhammadiyah 1 Pontianak.

\section{METODE PENELITIAN Jenis Penelitian}

Desain yang digunakan dalam penelitian ini adalah analitik observasional dengan pendekatan rancangan penelitian jenis crosssectional.

\section{Lokasi dan Waktu Penelitian}

Penelitian ini dilakukan di SMA Muhammadiyah 1 Pontianak dan dilaksanakan pada bulan Mei 2018 hingga Mei 2019.

\section{Populasi dan Sampel}

Populasi penelitian ini berjumlah 442 orang. Sampel diambil menggunakan metode simple random sampling.

\section{Pengumpulan Data}

Pengumpulan data dilakukan dengan mengukur tinggi dan berat badan untuk menentukan nilai IMT, kemudian acne vulgaris pada siswa-siswi diperiksa menggunakan Global Acne Grading Score lalu dilakukan pengisian kuesioner.

\section{Pengolahan dan Analisis Data}

Analisis data menggunakan software computer. Teknik analisis menggunakan analisis bivariat untuk menganalisis satu variabel bebas dan satu variabel terikat. Dalam penelitian ini untuk mengetahui hubungan IMT terhadap kejadian acne vulgaris. Analisis penelitian ini menggunakan uji regresi logistik. 


\section{HASIL PENELITIAN}

Karakteristik kejadian acne vulgaris, dan keparahan acne vulgaris dapat dilihat pada tabel 1 . berdasarkan umur, kelas, jenc kelamin,

Tabel 1 Karakteristik Umum Sampel Penelitian

\begin{tabular}{|c|c|c|}
\hline Karakteristik & Jumlah (orang) & Presentase $(\%)$ \\
\hline $\begin{array}{c}\text { Umur (tahun) } \\
14 \text { tahun } \\
15 \text { tahun } \\
16 \text { tahun } \\
17 \text { tahun } \\
18 \text { tahun }\end{array}$ & $\begin{array}{c}2 \\
27 \\
40 \\
12 \\
1\end{array}$ & $\begin{array}{c}2.4 \\
32.9 \\
48.8 \\
14.6 \\
1.3\end{array}$ \\
\hline Total & 82 & 100.0 \\
\hline $\begin{array}{c}\text { Kelas } \\
\text { X } \\
\text { XI }\end{array}$ & $\begin{array}{l}29 \\
53\end{array}$ & $\begin{array}{l}35.4 \\
64.6\end{array}$ \\
\hline Total & 82 & 100.0 \\
\hline $\begin{array}{c}\text { Jenis Kelamin } \\
\text { Perempuan } \\
\text { Laki-laki } \\
\text { Total }\end{array}$ & $\begin{array}{l}34 \\
48 \\
82\end{array}$ & $\begin{array}{l}41.5 \\
58.5 \\
\end{array}$ \\
\hline $\begin{array}{c}\text { Acne Vulgaris } \\
\text { Negatif } \\
\text { Positif } \\
\end{array}$ & $\begin{array}{l}32 \\
50 \\
82\end{array}$ & $\begin{array}{r}39.0 \\
61.0 \\
\end{array}$ \\
\hline Total & 82 & 100.0 \\
\hline $\begin{array}{l}\text { IMT } \\
\text { Underweight } \\
\text { Normal } \\
\text { Overweight } \\
\text { Obesitas }\end{array}$ & $\begin{array}{c}6 \\
55 \\
4 \\
17\end{array}$ & $\begin{array}{c}7.3 \\
67.1 \\
4.9 \\
20.7\end{array}$ \\
\hline Total & 82 & 100.0 \\
\hline $\begin{array}{l}\text { Keparahan } \\
\text { Negatif } \\
\text { Ringan } \\
\text { Sedang } \\
\text { Parah } \\
\text { Sangat Parah }\end{array}$ & $\begin{array}{c}33 \\
45 \\
4 \\
0 \\
0\end{array}$ & $\begin{array}{c}40.2 \\
54.9 \\
4.9 \\
0 \\
0\end{array}$ \\
\hline Total & 82 & 100.0 \\
\hline
\end{tabular}

Distribusi Usia terhadap Acne Vulgaris

Sampel penelitian berdasarkan usia yang menderita acne vulgaris terbanyak berusia 17 tahun berjumlah 9 orang (75\%). Distribusi jumlah sampel penelitian berdasarkan usia dapat dilihat pada tabel 2 .

Distribusi Kelas terhadap Acne Vulgaris

Distribusi kelas terhadap acne vulgaris menunjukkan kelas terbanyak yang mengalami acne vulgaris adalah kelas XI dengan jumlah 33 orang $(62.3 \%)$.

\section{Distribusi Jenis Kelamin terhadap Acne} Vulgaris

Distribusi jenis kelamin terhadap acne vulgaris menunjukkan insidensi acne vulgaris positif pada perempuan 21 orang (61.8\%), sedangkan pada laki-laki yang mengalami acne vulgaris positif berjumlah 29 orang $(60.4 \%)$. Hasil uji jenis kelamin terhadap acne vulgaris 
menunjukkan p-value 0.543 (>0.05) yang berarti secara statistik tidak terdapat hubungan antara jenis kelamin dengan kejadian acne vulgaris.

Tabel 2. Distribusi Usia, Kelas, dan Jenis Kelamin terhadap Kejadian Jerawat (Acne Vulgaris)

\begin{tabular}{|c|c|c|c|c|c|c|}
\hline \multirow{3}{*}{ Karakteristik } & \multicolumn{4}{|c|}{ Kejadian Jerawat (Acne Vulgaris) } & \multirow{2}{*}{\multicolumn{2}{|c|}{ Total }} \\
\hline & \multicolumn{2}{|c|}{ Acne Vulgaris (+) } & \multicolumn{2}{|c|}{ Acne Vulgaris (-) } & & \\
\hline & $\mathbf{n}$ & $\%$ & $\mathbf{n}$ & $\%$ & $\mathbf{n}$ & $\%$ \\
\hline \multicolumn{7}{|l|}{ Usia (tahun) } \\
\hline 14 tahun & 0 & 0.0 & 2 & 100.0 & 2 & 100.0 \\
\hline 15 tahun & 17 & 63.0 & 10 & 37.0 & 27 & 100.0 \\
\hline 16 tahun & 24 & 60.0 & 16 & 40.0 & 40 & 100.0 \\
\hline 17 tahun & 9 & 75.0 & 3 & 25.0 & 12 & 100.0 \\
\hline 18 tahun & 0 & 0.0 & 1 & 100.0 & 1 & 100.0 \\
\hline Total & 50 & 61.0 & 32 & 39.0 & 82 & 100.0 \\
\hline \multicolumn{7}{|l|}{ Kelas } \\
\hline $\mathrm{X}$ & 17 & 58.6 & 12 & 41.4 & 29 & 100.0 \\
\hline $\mathrm{XI}$ & 33 & 62.3 & 20 & 37.7 & 53 & 100.0 \\
\hline Total & 50 & 61.0 & 32 & 39.0 & 82 & 100.0 \\
\hline \multicolumn{7}{|l|}{ Jenis Kelamin } \\
\hline Perempuan & 21 & 61.8 & 13 & 38.2 & 34 & 100.0 \\
\hline Laki-laki & 29 & 60.4 & 19 & 39.6 & 48 & 100.0 \\
\hline Total & 50 & 61.0 & 32 & 39.0 & 82 & 100.0 \\
\hline
\end{tabular}

Distribusi Jenis Kelamin terhadap Tingkat Keparahan Acne Vulgaris

Hasil penelitian ini diketahui dari 82 sampel, $14(42.4 \%)$ orang perempuan tidak mengalami acne vulgaris, 19 orang $(42.2 \%)$ mengalami acne vulgaris ringan, dan 1 orang (25\%) mengalami acne vulgaris sedang. Lakilaki pada penelitian ini berjumlah 48 orang dengan 19 orang (57.6\%) tidak mengalami acne vulgaris, 26 orang (57.8\%) mengalami acne vulgaris ringan dan 3 orang (75\%) mengalami acne vulgaris sedang. Hasil uji jenis kelamin terhadap acne vulgaris menunjukkan p-value $1.000(>0.05)$ yang berarti secara statistik tidak terdapat hubungan antara jenis kelamin dengan keparahan acne vulgaris. Distribusi jumlah sampel penelitian berdasarkan jenis kelamin dapat dilihat pada tabel 3 di bawah ini.

Tabel 3. Distribusi Jenis Kelamin terhadap Keparahan Jerawat (Acne Vulgaris)

\begin{tabular}{lcccccccc}
\hline \multirow{2}{*}{ Karakteristik } & \multicolumn{3}{c}{ Jenis Kelamin } & \multicolumn{2}{c}{ Total } & \multirow{2}{*}{ P-value } \\
\cline { 2 - 6 } & \multicolumn{2}{c}{ Perempuan } & \multicolumn{2}{c}{ Laki-laki } & & \\
\cline { 2 - 6 } & $\mathbf{n}$ & $\mathbf{\%}$ & $\mathbf{n}$ & $\mathbf{\%}$ & $\mathbf{n}$ & $\mathbf{\%}$ & \\
\hline Keparahan & & & & & & & \\
$\quad$ Negatif & 14 & 42.4 & 19 & 57.6 & 33 & 100.0 & \\
Ringan & 19 & 42.2 & 26 & 57.8 & 45 & 100.0 & \\
Sedang & 1 & 25 & 3 & 75 & 4 & 100.0 & 1.000 \\
Parah & 0 & 0 & 0 & 0 & 0 & 0 & \\
Sangat Parah & 0 & 0 & 0 & 0 & 0 & 0 & \\
Total & 34 & 41.5 & 48 & 58.5 & 82 & 100.0 & \\
\hline
\end{tabular}




\section{Hubungan Antara IMT dan Kejadian Acne Vulgaris}

Hubungan IMT dan kejadian acne vulgaris diuji menggunakan uji statistik korelasi regresi logistik dengan menggunakan SPSS 23. Hasil uji menunjukkan terdapat hubungan korelasi positif yang bermakna antara IMT dan kejadian acne vulgaris $(\mathrm{p}=0.001, \mathrm{OR}=2.807)$. Hasil p-value $0.001 \quad(<0.05)$ menunjukkan menolak $\mathrm{H}_{0}$ yang berarti bahwa penambahan.
Variabel independen dapat memberikan pengaruh yang nyata. Nilai Hosmer and Lemeshow Test atau Goodness of Fit (GoF) sebesar $0.423(>0.05)$ sehingga menunjukkan bahwa pengujian hipotesis dapat dilakukan. Nilai OR 2.807 yang menunjukkan risiko acne vulgaris meningkat 2.807 sejalan dengan peningkatan IMT. Semakin meningkatnya IMT maka semakin berisiko seseorang mengalami acne vulgaris. Hasil uji regresi logistik disajikan dalam tabel 4 di bawah ini.

Tabel 4. Uji Regresi Logistik Hubungan IMT dan Kejadian Jerawat (Acne Vulgaris)

\begin{tabular}{cccccc}
\hline \multirow{2}{*}{ P-value } & \multirow{2}{*}{ GoF } & \multirow{2}{*}{ Koefisien Korelasi } & \multirow{2}{*}{ OR } & \multicolumn{2}{c}{ 95\% CI } \\
\cline { 5 - 6 } & & 1.032 & 2.807 & Lower & Upper \\
\hline 0.001 & 0.423 & 1.377 & 5.724 \\
\hline
\end{tabular}

Hubungan Antara Indeks Massa Tubuh dan Keparahan Acne Vulgaris

Hasil penelitian hubungan IMT dan keparahan acne vulgaris disajikan dalam tabel 5 dan diuji menggunakan uji Kruskal-Wallis menggunakan program Statistical Product and Service Solution (SPSS). Data menunjukkan keparahan acne vulgaris ringan maupun sedang pada obesitas lebih tinggi dibanding IMT yang lain, yakni dengan nilai presentasi pada tingkat ringan $88.4 \%$ dan sedang $5.8 \%$. Nilai persentase pada acne vulgaris negatif pada obesitas lebih rendah dibanding pada IMT lainnya, yakni dengan nilai 5.8\%. Hasil uji IMT terhadap keparahan acne vulgaris menunjukkan $p$-value $0.009 \quad(<0.05)$ yang berarti secara statistik terdapat hubungan antara jenis kelamin dengan kejadian acne vulgaris.

Tabel 5. Uji Kruskal-Wallis Hubungan IMT dan Keparahan Jerawat (Acne Vulgaris)

\begin{tabular}{lcccccc}
\hline Karakteristik & $\begin{array}{c}\text { Negatif } \\
(\mathbf{\%})\end{array}$ & $\begin{array}{c}\text { Ringan } \\
(\mathbf{\%})\end{array}$ & $\begin{array}{c}\text { Sedang } \\
(\mathbf{\%})\end{array}$ & $\begin{array}{c}\text { Parah } \\
(\mathbf{\%})\end{array}$ & $\begin{array}{c}\text { Sangat Parah } \\
(\mathbf{\%})\end{array}$ & P-value \\
\hline IMT & & & & & & \\
$\quad$ Underweight & 50.0 & 50.0 & 0 & 0 & 0 & \\
Normal & 50.9 & 43.6 & 5.5 & 0 & 0 & 0.009 \\
Overweight & 25 & 75.0 & 0 & 0 & 0 & \\
Obesitas & 5.8 & 88.4 & 5.8 & 0 & 0 & \\
Total & 40.2 & 54.9 & 4.9 & 0 & 0 & \\
\hline
\end{tabular}

\section{PEMBAHASAN}

Hasil penelitian menujukan kejadian acne vulgaris di SMA Muhammadiyah 1 Pontianak sebesar $61.0 \%$. Hasil ini sesuai dengan penelitian yang dilakukan oleh Sharma et al juga menunjukkan prevalensi kejadian acne vulgaris yang lebih tinggi dibanding yang tidak, yakni dengan rata-rata $72.3 \%$. Penelitian tersebut dilakukan di 3 sekolah dengan prevalensi masing-masing sekolah $74.6 \%$, $76.0 \%$ dan $65.0 \%$. Faktor yang mempengaruhi kejadian acne vulgaris menurut literatur di antaranya usia, riwayat keluarga, jenis kulit, diet, stres, frekuensi cuci muka, merokok dan cuaca (Sharma RK, et al, 2017). Kejadian obesitas pada penelitian ini sebesar $20.7 \%$. Obesitas di Indonesia pada tahun 2016 dengan IMT $>27$ tercatat sebesar 20.6\% (Kemenkes RI, 2016).

Jumlah sampel penelitian yang mengalami acne vulgaris berdasarkan usia didominasi oleh usia 17 tahun yakni $75.0 \%$. Hal ini sejalan dengan penelitian Noorbala bahwa penderita acne vulgaris tertinggi berada pada rentang usia 15 - 18 tahun (Noorbala MT, et al, 2013). Acne vulgaris sering terjadi pada saat pubertas. Prevalensi tertinggi biasanya terjadi pada pertengahan sampai akhir dekade kedua, 
dengan lebih dari $85 \%$ remaja mengalami acne vulgaris dan kemudian prevalensinya menurun setelahnya. Hal ini terjadi karena pengaruh androgen adrenal atau dehydroepiandrosterone sulfate (DHEAS) yang meningkat bersamaan dengan sekresi sebum pada masa pubertas (Neupane S, et al, 2018). Peningkatan sekresi hormon androgen yang menyebabkan pembesaran dan stimulasi berlebihan dari kelenjar sebasea pada folikel rambut atau poripori kulit. Sekresi sebum yang berlebih akibat proses tersebut bercampur dengan sel kulit mati dan bakteri di permukaan kulit sehingga menyumbat pori-pori. Bakteri tersebut bermultiplikasi dan menyebabkan inflamasi. Hal ini yang memicu terjadinya acne vulgaris (Ewadh MJ, et al, 2011). Acne vulgaris pada remaja juga berhubungan dengan peningkatan efek anabolik dari insulin dan GH selama masa rapid somatix growth menuju dewasa (Kurtoglu $\mathrm{S}$, et al, 2010).

Sampel berdasarkan jenis kelamin yang memiliki kejadian acne vulgaris di penelitian ini pada laki-laki dengan jumlah 29 orang $(60.4 \%)$ dan perempuan 21 orang (61.8\%). Hasil uji menunjukkan tidak terdapat hubungan yang signifikan antara jenis kelamin dan acne vulgaris. Penelitian Muthupalaniappen et al juga melaporkan prevalensi acne vulgaris baik perempuan maupun laki-laki menunjukkan hasil yang hampir sama dengan angka insidensi yang lebih tinggi terjadi pada perempuan. $(1: 1,1)$ (Kartheepan K, et al, 2015). Penelitian Ghodsi et al menunjukkan dari 1002 orang sampel tidak ada perbedaan signifikan antara gender dan keparahan acne vulgaris (Ghodsi $\mathrm{ZS}$, et al, 2009). Hasil tersebut dapat terjadi karena acne vulgaris oleh multifactorial (Kartheepan K, et al, 2015). Faktor yang menyebabkan acne vulgaris pada perempuan kemungkinan kompleks dan multifaktorial, misalnya karena kosmetik, genetik, jenis kulit oily dan diet yang memerlukan penelitian lebih lanjut (Lynn DD, et al, 2016). Faktor pada lakilaki yang mungkin berpengaruh di antara tingkat stres, paparan sinar matahari dan panas yang berlebih, dan keringat yang berlebih (ElAkawi Z, et al, 2006; Qidwai A, et al, 2017).

Hasil penelitian yang telah dilakukan menunjukkan insidensi acne vulgaris tertinggi pada obesitas yakni $94.1 \%$. Hasil penelitian juga menunjukkan terdapat hubungan antara IMT dengan kejadian acne vulgaris pada siswasiswi SMA Muhammadiyah 1 Pontianak. Hal ini sesuai dengan penelitian yang dilakukan oleh Lu dkk. yang memperoleh hasil angka IMT pasien dengan acne vulgaris lebih tinggi dibanding dengan yang tidak hal ini juga sejalan dengan tingkat keparahannya (Lu LY, et al, 2017). Penelitian yang dilakukan oleh Alan et al juga menunjukkan hasil yang sama dengan penelitian ini, yakni nilai IMT pada acne vulgaris yang parah lebih tinggi dibandingkan acne vulgaris ringan (Alan S, 2014).

Orang dengan obesitas memiliki jaringan lemak yang lebih banyak yang merupakan sumber produksi androgen. Pada orang yang mengalami obesitas terjadi hiperandrogenisme perifer yang dapat menyebabkan peningkatan aktivitas kelenjar sebasea dan produksi sebum yang merupakan faktor yang menyebabkan perkembangan acne vulgaris (Neupane et al, 2018). Insulin, androgen, growth hormone, dan insulin-like growth factors meningkat pada pasien obesitas dan mengaktifkan kelenjar sebasea yang mempengaruhi acne vulgaris ( $\mathrm{Lu} \mathrm{LY}$, et al, 2017).

\section{KESIMPULAN DAN SARAN}

Hasil uji menunjukkan terdapat hubungan korelasi positif yang bermakna antara IMT dan kejadian acne vulgaris. Kejadian acne vulgaris meningkat 2.807 kali seiring dengan peningkatan IMT pada siswa-siswi SMA Muhammadiyah 1 Pontianak. Status gizi siswasiswi SMA Muhammadiyah 1 Pontianak paling banyak dalam rentang normal. Sebanyak 50 (61\%) siswa-siswi di SMA Muhammadiyah 1 Pontianak mengalami acne vulgaris. Sebanyak 45 (54.9\%) siswa-siswi di SMA Muhammadiyah 1 Pontianak mengalami acne vulgaris derajat ringan dan 4 siswa-siswi lainnya (4.9\%) mengalami acne vulgaris derajat ringan sedang.

Siswa-siswi yang mengalami obesitas disarankan untuk berolahraga, menjaga pola makan, gaya hidupnya untuk mengembalikan IMT mereka dalam rentang normal serta mengurangi kejadian acne vulgaris yang berhubungan dengan IMT. Pihak sekolah dapat bekerja sama dengan instansi kesehatan setempat untuk melakukan penyuluhan kepada siswa-siswi terutama yang memiliki risiko tinggi mengalami acne vulgaris dengan kategori IMT obesitas. Pihak sekolah dapat bekerja sama dengan instansi kesehatan setempat untuk melakukan penyuluhan kepada 
siswa-siswi mengenai obesitas. Penelitian serupa dan lebih lanjut dengan populasi yang lebih luas, rentang usia yang lebih luas, dan pengendalian faktor-faktor perancu seperti faktor genetika, stres, higiene, dan jenis kulit sehingga data lebih akurat.

\section{DAFTAR PUSTAKA}

Alan S, C. E. (2014). Effects of hyperandrogenism and high body mass index on acne severity in women. Saudi Medical Journal, 35(8), 886-889.

Depkes RI. (2013). Riset Kesehatan Dasar. Jakarta: Depkes RI.

El-Akawi Z, N Nemr AL, A.-R. K. dan A.-A. M. (2006). Factor believed by jordanian acne patients to affect their acne condition. Eastern Mediteranean Health Journal, 12(6), 840-846.

Ewadh MJ, Shemran KA, A.-H. K. (2011). The correlation of some hormones with acne vulgaris. Int J Sci Nat, 2(4), 713-717.

Ghodsi ZS, Orawa H, Z. C. (2009). Prevalence, severity, and severity risk factors of acne in high school pupils: a communitybased study. Journal of Investigate Dermatology, 129, 2136-2140.

IDAI. (2013). Overview adolescents health problems and service. Retrieved January 17, 2018, from IDAI website: http://www.idai.or.id/ artikel/seputarkesehatan-anak/ overview-adolescenthealth-problems-and-services.

Kartheepan K, Suhail A, Mithuna V, P. L. (2015). Evaluation of common risk factors of acne in teenagers in batticaloa distric. IntSym.

Kemenkes RI. (2016). Profil kesehatan Indonesia tahun 2016. Jakarta: Kemenkes RI.

Kurtoglu S, Hatipoglu N, Masicioglu M, Kendirci M, K. M. (2010). Insulin resistance in obese children and adolescents: HOMA-IR cut-off levels in the prepubertal and pubertal periods. $J$ Clin Res Ped Endo, 2(3), 100-106.

Lailani TM. (2013). Hubungan antara peningkatan indeks massa tubuh dengan kejadian nyeri punggung bawah pada pasien rawat jalan di Poliklinik Saraf RSUD Dokter Soedarso Pontianak (Vol. 1). Universitas Tanjungpura.
Lu LY, Lai HY, Pan ZY, Wu ZX, C. W. (2017). Obese/overweight and the risk of acne vulgaris in Chinese adolescents and young adults. Hongkong $J$ Dermatol Venero, 25, 5-12.

Lynn DD, Umari T, Dunnick CA, D. R. (2016). The epidemiology of acne vulgaris in late adolescence. Adolescent Health, Medicine and Therapeutics, 7, 13-25.

Neupane S, Basnet S, S. D. (2018). Association between acne and body mass index: A hospital based cross sectional study. Nepal J Dermatology, Venerol Leprol, 16(1), 53-55.

Noorbala MT, Mozaffary B, N. M. (2013). Prevalence of acne and its impact on the quality of life in high school-aged adolescents in Yazd, Iran. J Pakistan Assoc Dermatologists, 23(2), 168-172.

Pranitasari ARD. (2011). Hubungan antara indeks massa tubuh dengan akne vulgaris. UNS.

Qidwai A, Pandey M, Shukla SK, Pandey A, K. R. (2017). Risk factors assessment for acne vulgaris in human and implications for public health intervention in North Central India: a survey-based study. Asian J Pharm Clin Res, 10(5), 404-410.

Sharma RK, Dogra S, Singh A, K. A. (2017). Epidemiological patterns of acne vulgaris among adolescents in North India: cross sectional study and brief review of literature. Pediatric Dermatology, 18(3), 196-201.

WHO. (2014). International programme on chemical safety: dermal exposure. Environmental Health Criteria. 228-229.

WHO. (2018). Global Health Observatory Data: overweight and obesity. Retrieved January 17, 2018, from http://www. who.int/gho/ncd/risk_factors/overweight _obesity/bmi_trends_adolescents/en/.

WHO. (2018). Health Topic: obesity. Retrieved January 17, 2018, from http://www. who.int/topics/obesity/en/.

Zaenglein AL, Parthy AL, Schlosser BJ, Alikhan A, Baldwin HE, Berson DS, et al. (2016). Guidelines of care for the management of acne vulgaris. Journal American Academy of Dermatology Elsevier, 74, 945-973. 